\title{
Stilbene levels and antioxidant activity of Vranec and Merlot wines from Macedonia: Effect of variety and enological practices
}

\author{
Sanja Kostadinović ${ }^{\mathrm{a}, \mathrm{c}, *}$, Andrea Wilkens ${ }^{\mathrm{a}}$, Marina Stefova ${ }^{\mathrm{b}}$, Violeta Ivanova ${ }^{\mathrm{c}}$, Borimir Vojnoski ${ }^{\mathrm{c}}$, \\ Hamed Mirhosseini ${ }^{\mathrm{d}}$, Peter Winterhalter ${ }^{\mathrm{a}}$ \\ a Institute of Food Chemistry, Technische Universität Braunschweig, Schleinitzstraße 20, 38106 Braunschweig, Germany \\ ${ }^{\mathrm{b}}$ Institute of Chemistry, Faculty of Natural Science and Mathematics, Sts. Cyril and Methodius University, Arhimedova bb, 1000 Skopje, Macedonia \\ 'Faculty of Agriculture, University "Goce Delčev", Krste Misirkov bb, 2000 Štip, Macedonia \\ d Department of Food Technology, Faculty of Food Science and Technology, University Putra Malaysia, Sri Serdang, 43400 UPM Serdang, Selangor, Malaysia
}

\section{A R T I C L E I N F O}

\section{Article history:}

Received 1 April 2012

Received in revised form 20 June 2012

Accepted 21 June 2012

Available online 14 July 2012

\section{Keywords:}

Wine

Stilbenes

trans-Resveratrol

trans-Piceid

Trolox Equivalent Antioxidant Activity

(TEAC)

Winemaking

Maceration time

Yeasts

$\mathrm{SO}_{2}$

\begin{abstract}
A B S T R A C T
The content of the stilbenes trans-resveratrol and piceid as well as the antioxidant activity of Macedonian red wines from the two main grape varieties Vranec and Merlot have been evaluated. The effects of time of maceration, type of yeast and the level of sulphur dioxide applied on stilbene content and antioxidant activity have been studied. The most important factor in winemaking technology is the maceration time since the highest concentrations of trans-resveratrol, piceid and highest antioxidant activity were found following 6 and 10 days of maceration. Concerning the yeast type, higher concentrations of trans-resveratrol and piceid have been obtained with French yeast "Levuline CHP" in comparison to Macedonian yeast "Vinalco". In contrast, the higher antioxidant activity of wines from both varieties of grapes was observed by application of Macedonian yeast "Vinalco".
\end{abstract}

(c) 2012 Elsevier Ltd. All rights reserved.

\section{Introduction}

Stilbenes belong to the non-flavonoid class of wine phenolic compounds and resveratrol is the major stilbene present in grapes and wines (Wilkens, Rentzsch, \& Winterhalter, 2008, chap. II). Resveratrol occurs in two isomeric forms, the trans- and cis-configured isomers. Trans-resveratrol or trans-3,5,4'-trihidroxystilbene is the most abundant form being mainly located in grape skins. Glucoconjugated forms of trans- and cis-resveratrol are known as piceids.

Generally, stilbenes are known as phytoalexins which can be biosynthesised from grapevines as a defence to fungal diseases, such as Botrytis cinerea, or abiotic stress and UV irradiation.

The antioxidant and antimicrobial efficiency of resveratrol provides health benefits, such as the prevention of cardiovascular diseases, arteriosclerosis and cancer. Originally, epidemiological studies indicated an inverse relationship between moderate wine

\footnotetext{
* Corresponding author at: Faculty of Agriculture, University “Goce Delčev", Krste Misirkov bb, 2000 Štip, Macedonia. Tel.: +38 972579133.

E-mail address: sanja.kostadinovik@ugd.edu.mk (S. Kostadinović).
}

consumption and the risk of coronary heart disease, the so-called "French Paradox" (Barnard \& Linter, 1992).

Comparisons between levels of resveratrol in different red wines from a single grape variety (mono-varietal red wines) and the level of resveratrol in red wines from different regions was also established. The average level of trans-piceid was found to be three times higher than that of trans-resveratrol. The content of resveratrol has been determined in white $(0.005-0.57 \mathrm{mg} / \mathrm{L})$ and red wines $(0.550-2.534 \mathrm{mg} / \mathrm{L}$ ) from Greece (Gerogiannaki-Christopoulou, Athanasopoulous, Kyriakidis, Gerogiannaki, \& Spanos, 2006; Kallithraka, Arvanitoyannis, El-Zajouli, \& Kefalas, 2001), in red wines from the Canary Islands $(2.06-3.75 \mathrm{mg} / \mathrm{L}$ ) (Rodríguez-Delgado, González, Pérez-Trujillo, \& García-Montelongo, 2002), in wines produced from grapes cultivated in the Snake River Valley (>1.91 mg/L) (Lee \& Rennaker, 2007), in red and rosé wines produced in the four designations of origin of Aragon (0.62-3.09 mg/ L) (Abril, Negueruela, Pérez, Juan, \& Estopañán, 2005), in red wines elaborated from Galician varieties (3.02-36.13 mg/L) (Feijóo, Moreno, \& Falqué, 2008), in Brazilian wines $(0.04-1.26 \mathrm{mg} / \mathrm{L}$ ) (Lucena et al., 2010), as well as in a wide range of commercial red and white wines from Japan $(0.2-1.5 \mathrm{mg} / \mathrm{L})$, France $(3.8-7.4 \mathrm{mg} / \mathrm{L})$ 
(Stervbo, Vang, \& Bonnesen, 2007) and Serbia (till $2.5 \mathrm{mg} / \mathrm{L}$ ) (Atanacković et al., 2012).

The antioxidant potential of wine is largely attributable to its phenolic composition which is determined by its flavonoid content. A common method for determining the antioxidant activity of wines is the 2,2'-azino-bis(3-ethylbenzthiazoline-6-sulphonic acid) radical cation $\left(\mathrm{ABTS}^{+}\right.$) method (Re et al., 1999). The TEAC (Trolox Equivalent Antioxidant Capacity) value which is measured for wine samples expresses the concentration of a Trolox solution whose antioxidant activity is identical to that of the wine itself. This index is defined as the millimolar concentration of a Trolox solution whose antioxidant capacity is equivalent to a $1.0 \mathrm{mM}$ solution of the sample under study. Effects of some prefermentative treatments (e.g. addition of $\mathrm{SO}_{2}$ and ascorbic acid before grape crushing or must hyperoxidation) on the final resveratrol content in red wine have been studied (Castellari, Spinabelli, Riponi, \& Amati, 1998). It was demonstrated that lactic acid bacteria can impact resveratrol and piceid levels in wines (Poussier, GuillouxBenatier, Torres, Heras, \& Adrian, 2003). According to the findings of the research group of Vrhovsek, different yeast strains can significantly affect the resveratrol content in wine, except that of the cis-resveratrol glucoside (Vrhovsek, Wendelin, \& Eder, 1997). Increases in the levels of resveratrol after malolactic fermentation have been shown to be a result of glycoside breakage of piceid primarily concentrated in the grape skins (Pezet \& Cuenat, 1996). Further studies have examined the effect of different types of yeast (Vacca, Leccis, Fenu, Pretti, \& Farris, 1997) and the improvement of enzymatic hydrolysis with regard to higher levels of resveratrol in wine (La Torre et al., 2004).

The influence of temperature, pre- and post-fermentative factors, the influence of yeast and other factors of the wine-making process on the phenolic compounds of wines has been the focus of many studies (Caridi, Cufari, Lovino, Palumbo, \& Tedesco, 2004; Gil-Muñoz, Gómez-Plaza, Martínez, \& López-Roca, 1999; Gil-Muñoz, Gómez-Plaza, Martínez, \& López-Roca, 1997; Mazza, Fukumoto, Delaquis, Girard, \& Ewert, 1999). The group of Kovac found that the length of maceration time and the addition of high quantities of pomace, seeds and must increased the concentration of catechines and proanthocyanidins in wines (Kovac, Alonso, Bourzeix, \& Revilla, 1992). The group of Budić-Leto studied the influence of maceration time on the concentration of polyphenolic compounds in autochthonous cultivar 'Plavac mali' (Vitis vinifera L.). The results indicated that prolonged maceration time can increase the concentrations of proanthocyanidins and decrease the content of anthocyanins (Budić-Leto, Gracin, Lovrić, \& Vrhovsek 2008).

It is obvious that there are already many studies published on resveratrol and the antioxidative potential of wine, but, until now, there have been no published results about the level of resveratrol and the antioxidant activity of Macedonian wines. Therefore, the main objective of this study was to examine the content of resveratrol and piceid in Vranec and Merlot wines produced under different winemaking conditions, as well as the resulting antioxidant capacity. This included the application of different maceration times $\left(3,6\right.$, and 10 days), $\mathrm{SO}_{2}$ dosage and a study of the effect of different types of yeast.

\section{Materials and methods}

\subsection{Samples and winemaking process}

Twelve red wines from Vranec grape variety (V1-V12) and 12 red wines from Merlot variety (M1-M12) produced at the Experimental Laboratory of the Department for Enology, Institute of Agriculture, Skopje, Macedonia, were the subject of this investigation.
In brief, grapes from both varieties were harvested at optimal maturity (22 ${ }^{\circ}$ Brix for Vranec and $20^{\circ}$ Brix for Merlot) and, after crushing, the grape mash was divided into 12 lots collected in $25 \mathrm{~L}$ plastic fermentation tanks. Aqueous solutions of potassium metabisulphite were added to the mashes of both varieties to give six tanks with $30 \mathrm{mg} / \mathrm{L}$ of total $\mathrm{SO}_{2}$ and six tanks with $70 \mathrm{mg} / \mathrm{L}$ of total $\mathrm{SO}_{2}$. Two yeasts (Saccharomyces cerevisiae) were used for fermentation: Vinalco, selected by Yeast Factory, Bitola, R. Macedonia, and Levuline, isolated in the terroirs of Champagne and selected by CIVC 8130 (Interprofessional Committee of Champagne Wines), France. Vinalco $(20 \mathrm{~g} / 100 \mathrm{~L})$ was applied to three lots containing $30 \mathrm{mg} / \mathrm{L}$ of $\mathrm{SO}_{2}$ and three other lots containing $70 \mathrm{mg} / \mathrm{L}$ of $\mathrm{SO}_{2}$ of each variety. Levuline $(30 \mathrm{~g} / 100 \mathrm{~L})$ was applied to the other lots of both varieties.

Maceration times of 3, 6, and 10 days were applied for wine production of both varieties, each containing two doses of $\mathrm{SO}_{2}$ and two yeasts for fermentation. After stabilisation for 2 weeks (at $-4{ }^{\circ} \mathrm{C}$ ), wines were bottled and analysed after 2 years of storage.

\subsection{Reagents}

trans-Resveratrol and trans-piceid were obtained from Phytolab, Vestenbergsgreuth, Germany. Distilled water, acetonitrile, methanol, ethanol and glacial acetic acid were purchased from Merck, Germany. All solvents used were HPLC grade. 2,2'-azino-bis(3-ethylbenzthiazoline-6-sulphonic acid) $\left(\right.$ ABTS $^{+}$) in the crystallised diammonium salt form, horseradish peroxidase type VI-A, hydrogen peroxide 30\% (v/v) and Trolox (6-hydroxy-2,5,7,8-tetramethyl-chroman-2-carboxylic acid, a water soluble tocopherol analogue), were also obtained from Merck, Germany.

\subsection{TEAC assay}

The antioxidant activity of wines was determined using the ABTS $^{+}$method for screening of the antioxidant activity as a decolorisation assay applicable to both lipophilic and hydrophilic antioxidants (Re et al., 1999). The assay involves direct production of the blue/green ABTS $^{+}$chromophore through reaction between $\mathrm{ABTS}^{+}$and potassium persulphate. The product has absorption maxima at 414, 645, 734 and $815 \mathrm{~nm}$.

The method employed in this study gives a measure of the antioxidant capacity of red wines produced under different conditions. For this purpose, $10 \mathrm{~mL}$ of ABTS solution was prepared. The ABTS solution was made from $38.43 \mathrm{mg}$ of ABTS and $6.90 \mathrm{mg}$ of $\mathrm{K}_{2} \mathrm{~S}_{2} \mathrm{O}_{2}$ and made up with Nanopure water to volume. For the calibration curve, $5 \mathrm{~mL}$ solution of $12.52 \mathrm{mg}$ of Trolox standard were diluted with ethanol (97\%) and four standard solutions were prepared for the calibration curve $(y=0.2523 \mathrm{X}+0.0453$ and $R=0.9996)$ with concentrations of $250,500,750$, and $1000 \mathrm{mmol} / 5 \mathrm{~mL}$, respectively. The measured values for antioxidant activity of the wines were recorded after $6 \mathrm{~min}$. A UV/vis spectrophotometer Bruker IFS 66 was used for the analyses. The absorbance was measured at $734 \mathrm{~nm}$ at room temperature.

\subsection{HPLC analysis}

A Chromatograph Agilent Technologies 1200 Series, with Jasco AS-950 sampler, an auto injector (20 $\mu \mathrm{L}$ injection volume) was used for the analyses. Mass Selective Detector type Bruker Daltonics HCT Ultra was used for identification of trans-resveratrol (under negative ion mode) and trans-piceid. For quantification purposes, a Jasco MD-1510 Multiwavelength Detector was applied. Separation of the components was performed by using a C18 Luna column ( $5 \mu \mathrm{m} \times 4,6 \mathrm{~mm} \times 25 \mathrm{~cm}$, Phenomenex). The mobile phase flow rate was $0.5 \mathrm{~mL} / \mathrm{min}$. The eluents were: solvent $\mathrm{A}$ (water:acetic 
acid, 98:2, v/v) and solvent B: acetonitrile. Gradient elution was employed: 0-5 min, 85-80\%; 5-15 min, 80-72\%; 15-50 min, 72$58 \%$, and $50-52 \mathrm{~min}, 58-0 \%$ solvent A. Quantification of trans-resveratrol and trans-piceid was performed with external calibration at a wavelength of $306 \mathrm{~nm}$ using a standard solution of resveratrol and its glucoside. cis-Configured forms of resveratrol and piceid at $286 \mathrm{~nm}$ were below limit of quantification in all wines and below limit of detection in most of the wines.

Standard solutions used for calibration were prepared in methanol and kept in the dark at $-5{ }^{\circ} \mathrm{C}$. The calibration curves $(y=12323 x-1779.7$ for trans-resveratrol and $y=17008 x-11211$ for trans-piceid) were established by plotting the area of peaks against different concentrations of trans-resveratrol (varying from 0.1 to $20 \mathrm{mg} / \mathrm{L}$ ) and for trans-piceid (varying from 0.5 to $21 \mathrm{mg} / \mathrm{L}$ ) with correlation factor 0.9998 for trans-resveratrol and 0.9992 for trans-piceid, respectively.

\subsection{Statistical treatment}

The data for stilbenes content and antioxidant activity were subjected to the General Linear Model (GLM) to determine the significant main and interaction effects $(p<0.05)$ of independent variables, namely, type of yeast (Macedonian yeast Vinalco and French yeast Levuline), maceration time (3, 6 and 10 days) and $\mathrm{SO}_{2}$ content $(30$ and $70 \mathrm{mg} / \mathrm{L}$ ) on the level of trans-resveratrol and transpiceid in 24 Macedonian red wines from the varieties Vranec and Merlot. The corresponding variables are statistically significant $(p<0.05)$ if the absolute $F$ ratio becomes larger and the $p$-value becomes smaller. The data analysis was performed by using the Minitab software v. 13.2 (Minitab Inc., State College, PA, USA).

\section{Results and discussion}

The concentration of trans-resveratrol and trans-piceid and the resulting antioxidant activity was determined in 12 Vranec and 12 Merlot wines (Tables 1 and 2). A main objective of the study was to determine the effect of the applied wine-making techniques on the content of stilbenes. HPLC-MS analysis was used to identify the presence of stilbenes in the wine samples. Thus, trans-resveratrol detected in Merlot wines produced the deprotonated ion $[\mathrm{M}-\mathrm{H}]^{-}$ in negative ion mode at $m / z$ 227. Trans-piceid was detected in wines from both varieties and the $[\mathrm{M}-\mathrm{H}]^{-}$deprotonated molecular ion observed at $m / z 389$ in negative mode, forming fragment ion at $\mathrm{m} / \mathrm{z} 227$ corresponding to the resveratrol moiety by elimination of the glucose group (-162 Da).

\subsection{Effect of variety}

In Merlot wines, both trans-resveratrol and trans-piceid were detected, whereas in Vranec wines only trans-piceid was present. As shown in Tables 1 and 2, the contents of trans-piceid in Merlot wines were higher compared to Vranec wines obtained under the same vinification conditions. The biggest difference in the concentration of trans-piceid in favour of Merlot wines was detected in wines produced with 3 days of maceration time (V1M1-V4M4).

The aglycone form, i.e. free trans-resveratrol, is formed after enzymatic cleavage of piceid during the wine making process (La Torre et al., 2004). Because of the low content of trans-piceid in Vranec wines, it was not possible to detect the aglycone in this variety.

Merlot wine M8 produced with 6 days of maceration using French yeast and $70 \mathrm{ppm} \mathrm{SO}_{2}$ contains a high concentration of trans-piceid $(4.10 \pm 0.86 \mathrm{mg} / \mathrm{L})$ in comparison with other wines produced with 6 days of maceration time, but has an extremely low concentration of trans-resveratrol. This can be explained by an uncompleted enzymatic cleavage of trans-piceid during the winemaking process.

Comparing the results of this study related to the concentrations of trans-resveratrol in Merlot and Vranec wines from Macedonia and those published for Merlot wines from different regions of the world, it can be concluded that Macedonian Merlot and Vranec wines have lower concentrations of trans-resveratrol. Nevertheless, the concentrations are similar to trans-resveratrol concentrations in Merlot wines from Japan $(0.6-2.1 \mathrm{mg} / \mathrm{L})$, USA (0.4-2.7 mg/L), Greece (n.d. $-2.5 \mathrm{mg} / \mathrm{L}$ ), China (n.d. $-3.2 \mathrm{mg} / \mathrm{L}$ ), South America $(0.8-2.2 \mathrm{mg} / \mathrm{L})$ and Chile $(0.8-1.6 \mathrm{mg} / \mathrm{L})$ (Stervbo et al., 2007), red wines from Aragón (0.32-4.44 mg/L) (Abril et al., 2005), some red wines from the Galician region (Feijóo et al., 2008) and red wines from Hungarian Vanálly region (0.2$3.2 \mathrm{mg} / \mathrm{L}$ ) (Pour Nikfardjam, Márk, Avar, Figler, \& Ohmacht, 2006). Regarding the level of trans-piceid in both varieties of red wines, the level is similar to the level of the compound in red wines from Japan (0.17-3.54 mg/L) and USA (n.d.-0.59 mg/L) (Stervbo et al., 2007). These concentrations are expected because of the similar climatic conditions with approximate temperature in the range between 24 and $33^{\circ} \mathrm{C}$ during the summer period coupled with a lack of significant rainfall.

Results obtained for the antioxidant activity (TEAC assay) of Vranec wines were in the range of 3.44 for wine produced with 3 days of maceration time, by application of French yeast and $30 \mathrm{ppm} \mathrm{SO}$ and 10.99 for wine produced with 10 days of maceration time, French yeast and $70 \mathrm{ppm} \mathrm{SO}_{2}$.

Table 1

Concentration of trans-piceid and TEAC values in Vranec wines.

\begin{tabular}{|c|c|c|c|c|c|}
\hline & Days of maceration & Type of yeast & Concentration of $\mathrm{SO}_{2}(\mathrm{mg} / \mathrm{L})$ & trans-Piceid ${ }^{\mathrm{a}}(\mathrm{mg} / \mathrm{L})$ & TEAC $^{\mathrm{b}}(6 \mathrm{~min})$ \\
\hline V1 & 3 & Macedonian & 30 & $0.23 \pm 0.00$ & $4.10 \pm 0.01$ \\
\hline V2 & 3 & French & 30 & $0.56 \pm 0.00$ & $3.44 \pm 0.22$ \\
\hline V3 & 3 & Macedonian & 70 & $0.13 \pm 0.02$ & $6.24 \pm 0.21$ \\
\hline V4 & 3 & French & 70 & $0.20 \pm 0.09$ & $5.75 \pm 0.58$ \\
\hline V5 & 6 & Macedonian & 30 & $0.94 \pm 0.01$ & $8.74 \pm 0.22$ \\
\hline V6 & 6 & French & 30 & $1.49 \pm 0.00$ & $8.68 \pm 0.56$ \\
\hline V7 & 6 & Macedonian & 70 & $1.48 \pm 0.00$ & $9.38 \pm 0.28$ \\
\hline V8 & 6 & French & 70 & $1.49 \pm 0.01$ & $8.14 \pm 0.19$ \\
\hline V9 & 10 & Macedonian & 30 & $0.87 \pm 0.00$ & $7.13 \pm 0.10$ \\
\hline V10 & 10 & French & 30 & $1.58 \pm 0.05$ & $9.94 \pm 0.07$ \\
\hline V11 & 10 & Macedonian & 70 & $0.88 \pm 0.02$ & $10.03 \pm 0.17$ \\
\hline V12 & 10 & French & 70 & $2.24 \pm 0.08$ & $10.99 \pm 0.74$ \\
\hline
\end{tabular}

${ }^{a}$ Concentrations are expressed in $\mathrm{mg} / \mathrm{L} \pm \mathrm{SD}$ of two replicates.

b Expressed as mmol Trolox per litre. Each value corresponds to the mean and standard deviation of two repetitions \pm SD. 
Table 2

Concentration of trans-piceid, trans-resveratrol and TEAC values in Merlot wines.

\begin{tabular}{|c|c|c|c|c|c|c|}
\hline & Days of maceration & Type of yeast & Concentration of $\mathrm{SO}_{2}(\mathrm{mg} / \mathrm{L})$ & trans-Piceid $^{\mathrm{a}}(\mathrm{mg} / \mathrm{L})$ & trans-Resveratrol $^{\mathrm{a}}(\mathrm{mg} / \mathrm{L})$ & TEAC $^{\mathrm{b}}(6 \mathrm{~min})$ \\
\hline M1 & 3 & Macedonian & 30 & $2.17 \pm 0.21$ & $0.22 \pm 0.19$ & $6.66 \pm 0.50$ \\
\hline M2 & 3 & French & 30 & $2.91 \pm 0.07$ & $0.81 \pm 0.07$ & $4.72 \pm 0.01$ \\
\hline M3 & 3 & Macedonian & 70 & $2.54 \pm 0.19$ & $0.22 \pm 0.05$ & $6.88 \pm 0.00$ \\
\hline M4 & 3 & French & 70 & $2.75 \pm 1.00$ & $0.30 \pm 0.10$ & $5.36 \pm 0.21$ \\
\hline M5 & 6 & Macedonian & 30 & $2.95 \pm 1.38$ & $1.49 \pm 0.06$ & $6.25 \pm 0.07$ \\
\hline M6 & 6 & French & 30 & $3.83 \pm 0.21$ & $1.22 \pm 0.09$ & $5.60 \pm 0.21$ \\
\hline M7 & 6 & Macedonian & 70 & $3.18 \pm 0.76$ & $0.89 \pm 0.00$ & $6.60 \pm 0.12$ \\
\hline M8 & 6 & French & 70 & $4.10 \pm 0.86$ & $0.00 \pm 0.00$ & $6.00 \pm 0.07$ \\
\hline M9 & 10 & Macedonian & 30 & $4.21 \pm 0.70$ & $0.43 \pm 0.06$ & $8.98 \pm 0.23$ \\
\hline M10 & 10 & French & 30 & $4.65 \pm 0.46$ & $1.43 \pm 0.19$ & $7.91 \pm 0.05$ \\
\hline M11 & 10 & Macedonian & 70 & $2.89 \pm 0.57$ & $0.44 \pm 0.09$ & $8.65 \pm 0.14$ \\
\hline M12 & 10 & French & 70 & $4.48 \pm 0.18$ & $1.75 \pm 0.21$ & $7.01 \pm 0.03$ \\
\hline
\end{tabular}

a Concentrations are expressed in $\mathrm{mg} / \mathrm{L} \pm \mathrm{SD}$ of two replicates.

b Expressed as mmol Trolox per litre. Each value corresponds to the mean and standard deviation of two repetitions \pm SD.

The antioxidant activity of Merlot wines was in the range from 4.72 for wine produced with 3 days of maceration time, French yeast and $30 \mathrm{ppm} \mathrm{SO}_{2}$ to 8.98 for wine with 10 days of maceration time, Macedonian yeast and $30 \mathrm{ppm} \mathrm{SO}_{2}$. Generally speaking, from the results presented in Tables 1 and 2, Vranec wines had a higher antioxidant activity than Merlot wines.

\subsection{Effect of maceration time}

Maceration time influences significantly the extraction of stilbenes from grapes into the wine. According to the results shown in Tables 1 and 2, it can be seen that the lowest concentration of trans-piceid was detected in Vranec wine V3 produced with a maceration time of 3 days, by adding $70 \mathrm{ppm}$ of $\mathrm{SO}_{2}$ and by using the Macedonian yeast Vinalco. The results suggest that the concentration of resveratrol and piceid in 3 days of maceration time is very low, because of the very short time of extraction and lower concentration of ethanol. The solubilities of resveratrol and piceid are higher in ethanol; hence the extraction of both stilbenes is more efficient at the last stage of wine-making when the concentration of ethanol is higher following the metabolic activity of yeasts. These results are in accordance with the findings of Pezet and Cuenat (1996) who explained significantly higher concentrations of resveratrol up to 6 days of maceration by the increased concentration of ethanol in wines.

Prolongation of the extraction time increases the concentration of trans-resveratrol and trans-piceid. Consequently, the highest concentration of trans-piceid is detected in Merlot wine M10, produced with 10 days of maceration time using French yeast Levuline and $30 \mathrm{ppm}$ of $\mathrm{SO}_{2}$. Similarly, the highest concentration of trans-resveratrol is detected in Merlot wine M12 with 10 days of maceration using French yeast and $70 \mathrm{ppm} \mathrm{SO}_{2}$ (Table 2). However, Merlot and Vranec wines with relatively low concentrations of trans-resveratrol and trans-piceid reached maximal concentrations of both stilbenes already after a shorter period (i.e. after 6 days of maceration). These results are in accordance with the findings of Pezet and Cuenat (1996) and Vrhovsek et al. (1997) who stated that after five or six days of maceration, the concentration of trans-piceid starts to decrease due to the enzymatic cleavage of the glycosidic bond. Another possible explanation for the observed decreasing levels of trans-resveratrol from 6 to 10 days of maceration time could be due to the fixation of the yeasts, as occurs for other wine components such as anthocyanins, thiols or volatile phenols (Poussier et al., 2003). This behaviour indicates the possibility of metabolism of resveratrol by yeasts. Hence, M10 wine produced by application of French yeast Levuline reached the maximal concentration of resveratrol $(4.65 \pm 0.46 \mathrm{mg} / \mathrm{L})$ at 10 days of maceration time.
The effect of maceration time on the level of trans-piceid is statistically significant ( $p$-value is 0.027 for Merlot wines and 0.000 for Vranec wines). The results are presented in Table 3. Similarly, the effect of maceration time on the concentration of trans-resveratrol in Merlot wines is statistically significant ( $p$-value is 0.000 ). Interactions between two factors, maceration time and type of yeasts (factor $x_{1} x_{2}$ ), and maceration time and concentration of $\mathrm{SO}_{2}$ (factor $x_{1} x_{3}$ ) are also significant for trans-piceid in Vranec wines and trans-resveratrol in Merlot wines.

Interaction between factors is significant only for trans-piceid in Vranec wines and trans-resveratrol in Merlot wines because those concentrations were much lower in comparison with the concentrations of trans-piceid in Merlot wines. At the beginning of maceration when the concentrations of trans-piceid in Vranec wines and trans-resveratrol in Merlot wines were lower, the amount of $\mathrm{SO}_{2}$ did not play a significant role in extraction. At the end of maceration when the concentration of both stilbenes is higher, the effect of $\mathrm{SO}_{2}$ is to stimulate the extraction of the trans-piceid from $1.58 \pm 0.05 \mathrm{mg} / \mathrm{L}$ in $\mathrm{V} 10$ to $2.24 \pm 0.08 \mathrm{mg} / \mathrm{L}$ in V12 wine. Regarding the interaction between maceration time and yeast, the difference between concentrations of trans-resveratrol in M9 and M10 wines and M11 and M12 wines is higher for 10 days than for 3 days of maceration.

Maceration time had the strongest influence on the antioxidant activity of the wines. It is clear that all wines had their lowest antioxidant capacity after 3 days of maceration. The contact between the seeds and skins of the grapes was not long enough for complete extraction due to the lower concentration of ethanol at the

Table 3

Significant probability ( $p$-values and $F$-ratio) of the independent variable effects (maceration time, type of yeast, and $\mathrm{SO}_{2}$ concentration level).

\begin{tabular}{|c|c|c|c|c|c|c|}
\hline \multirow[t]{2}{*}{ Responsible variables } & \multicolumn{3}{|c|}{ Main effects } & \multicolumn{3}{|c|}{ Interaction effects } \\
\hline & $x_{1}$ & $x_{2}$ & $x_{3}$ & $x_{1} x_{2}$ & $x_{1} x_{3}$ & $x_{2} x_{3}$ \\
\hline \multicolumn{7}{|c|}{ trans-Piceid (Merlot wines) } \\
\hline$p$-Value & $0.027^{a}$ & 0.811 & 0.053 & 0.502 & 0.816 & 0.850 \\
\hline F-ratio & 4.71 & 0.06 & 4.49 & 0.72 & 0.21 & 0.04 \\
\hline \multicolumn{7}{|c|}{ trans-Resveratrol (Merlot wines) } \\
\hline$p$-Value & $\mathbf{0 . 0 0 0} 0^{\mathrm{a}}$ & $0.001^{\mathrm{a}}$ & $\mathbf{0 . 0 0 2 ^ { \mathrm { a } }}$ & $0.000^{\mathrm{a}}$ & $0.000^{\mathrm{a}}$ & 0.115 \\
\hline F-ratio & 21.12 & 15.89 & 13.64 & 14.08 & 36.08 & 2.83 \\
\hline \multicolumn{7}{|c|}{ trans-Piceid (Vranec wines) } \\
\hline$p$-Value & $\mathbf{0 . 0 0 0} 0^{\mathrm{a}}$ & $\mathbf{0 . 0 0 0 ^ { \mathrm { a } }}$ & 0.116 & $0.001^{\mathrm{a}}$ & $0.016{ }^{\mathrm{a}}$ & 0.720 \\
\hline F-ratio & 95.68 & 45.76 & 2.81 & 12.79 & 5.62 & 0.13 \\
\hline
\end{tabular}

$x_{1}, x_{2}$ and $x_{3}$ represent the main or single effect of maceration time, type of yeast, and $\mathrm{SO}_{2}$ concentration level, respectively.

$x_{1} x_{2}, x_{1} x_{3}$, and $x_{2} x_{3}$ represent the interaction between maceration time and type of yeast, interaction between maceration time and $\mathrm{SO}_{2}$ concentration level and interaction between type of yeast and $\mathrm{SO}_{2}$ concentration level, respectively.

a Significant at $p<0.05$. 
Table 4

Models for the General Linear Model (GLM) for Vranec wines.

\begin{tabular}{|c|c|c|c|c|c|c|c|}
\hline \multirow[t]{2}{*}{ Response variable } & & \multicolumn{3}{|c|}{ Main effects } & \multicolumn{3}{|c|}{ Interaction effects } \\
\hline & & $x_{1}$ & $x_{2}$ & $x_{3}$ & $x_{1} x_{2}$ & $x_{1} x_{3}$ & $x_{2} x_{3}$ \\
\hline \multirow[t]{2}{*}{ Antioxidant activity } & $p$-Value & $0.000^{\mathrm{a}}$ & $0.015^{\mathrm{a}}$ & $\mathbf{0 . 0 0 0}^{\mathrm{a}}$ & $0.004^{\mathrm{a}}$ & $\mathbf{0 . 0 0 0}^{\mathrm{a}}$ & 0.354 \\
\hline & F-ratio & 298.34 & 7.75 & 143.63 & 8.23 & 32.04 & 0.09 \\
\hline
\end{tabular}

$x_{i}$ : the estimated regression coefficient for the main effects.

$x_{i} x_{j}$ : the estimated regression coefficient for the interaction effects.

1 , Time of maceration; 2 , Type of yeast; 3 , Concentration of sulphur dioxide.

a Significant $(p<0.05)$.

beginning of the vinification. Most of the Vranec wines showed maximal extraction during 6 days of maceration time. As can be seen from the results in Table 1, only the increase in antioxidant capacity for 10 days observed for wine V12 is significant since the measured activity arises from 8.14 to 10.99 as well as the difference of antioxidant activity of wines V6 and V10. On the other hand, the difference between levels of 9.38 in wine V7 to 10.03 in wine V11 was not statistically significant. This finding is in agreement with the findings of Kovac et al. (1992) who showed that maximal extraction of polyphenols was during 6 to 7 days for the same grape variety. During prolonged maceration, the concentration of proanthocyanidins increases and the level of anthocyanins decreases which can be the reason for maximal antioxidant activity during 6 days of maceration time (Budić-Leto et al., 2008; Mazza et al., 1999; Spranger et al., 2004).

Merlot wines showed a maximum antioxidant activity as a result of prolonged pomace contact. Lower concentration of polyphenolics probably needs a longer period of extraction which resulted in the highest yields of polyphenolics after 10 days of maceration.

Statistical analysis for Vranec and Merlot wines in Tables 4 and 5 proved that maceration time has the highest effect on antioxidant activity of the wines ( $x_{1}$ factor is 0.000 for both types of wines).

\subsection{Effect of yeast}

All Vranec wines contain higher concentrations of trans-piceid after application of French yeast compared to the application of Macedonian yeast (Table 1). The concentration of trans-piceid in V2 and V4 produced by application of French yeast is twice the concentration in wines V1 and V3 produced under the same vinification conditions using Macedonian yeast Vinalco. The difference between the concentrations of trans-piceid in V9 and V10 is also twice as large as the difference in concentrations of piceid in V11 and V12 Vranec wines. This relationship is in agreement with results from Vacca et al. (1997) who explained that the difference in levels of resveratrol in wines is a result of the different types of yeasts applied during winemaking.

A higher concentration of trans-piceid was also detected in Merlot wines produced with French yeast compared to wines produced with Macedonian yeast (Table 2). However, the difference was not statistically significant as the $p$-values from the General Linear Model for factor $x_{2}$ (yeast factor) was 0.811 . From Table 2, it can be seen that the concentration of trans-piceid did not increase rapidly because the free aglycone form started to increase from day 3 until day 10 of maceration time. This is in accordance with the explanation of Vrhovsek et al. (1997), suggesting that the highest $\beta$-glucosidase activity of yeast was observed after 4 days of maceration time when the concentration of resveratrol increases.

Regarding trans-resveratrol levels in Merlot wines, Table 2 indicates that the concentrations in wines produced with the French yeast Levuline are, in most cases, higher than in wines produced with the Macedonian yeast Vinalco. The concentration of trans-resveratrol in Merlot wine M1 was $0.22 \pm 0.19$ compared with a concentration of $0.81 \pm 0.07 \mathrm{mg} / \mathrm{L}$ in wine $\mathrm{M} 2$ prepared using different types of yeast. The concentration of trans-resveratrol in Merlot wines M10 and M12 produced with 10 days of maceration time and French yeast "Levuline CHP" is approximately four times higher compared to the concentration in the corresponding wines M9 and M11 which were produced with Macedonian yeast "Vinalco". Statistical analysis indicates that this difference is statistically significant ( $p$-value of 0.001 ). Moreover, the interaction between maceration time and yeast (factor $x_{1} x_{2}$ ) has also a significant effect ( $p$-value of 0.000 ) since the differences in concentration of transresveratrol in wines produced by French yeast and Macedonian yeast increases noticeably from day 3 to 10 of maceration time.

The type of the yeast also influenced the antioxidant activity of the wines. It is noticeable that in wines produced with Macedonian yeast "Vinalco" higher antioxidant activity was observed compared to the wines produced with French yeast "Levuline CHP" (Tables 1 and 2).

Morata and co-workers found that different anthocyanins had different affinity to the cell wall of the different strains of S. cerevisiae yeasts. According to their findings, acetyl derivatives ( $p$-coumaroyl and acetyl) were better adsorbed than non-acyl derivatives. Also, anthocyanins with a greater degree of methoxylation (malvidin and peonidin) were better adsorbed than were the hydroxylated anthocyanins (delphinidin and petunidin). It has been concluded that adsorption involves a hydrophobic interaction (Morata et al., 2003). Different S. cerevisiae strains had the highest influence on anthocyanins and hydroxycinnamic acid in

Table 5

Models for the General Linear Model (GLM) for Merlot wines.

\begin{tabular}{|c|c|c|c|c|c|c|c|}
\hline \multirow[t]{2}{*}{ Response variable } & & \multicolumn{3}{|c|}{ Main effects } & \multicolumn{3}{|c|}{ Interaction effects } \\
\hline & & $x_{1}$ & $x_{2}$ & $x_{3}$ & $\mathrm{x}_{1} x_{2}$ & $x_{1} x_{3}$ & $x_{2} x_{3}$ \\
\hline \multirow[t]{2}{*}{ Antioxidant activity } & $p$-Value & $0.000^{a}$ & $0.000^{\mathrm{a}}$ & $0.123^{a}$ & $\mathbf{0 . 0 0 1}^{\mathrm{a}}$ & $0.000^{\mathrm{a}}$ & 0.476 \\
\hline & F-ratio & 262.86 & 149.65 & 2.70 & 12.39 & 18.04 & 0.54 \\
\hline
\end{tabular}

$x_{i}$ : the estimated regression coefficient for the main effects.

$x_{i} x_{j}$ : the estimated regression coefficient for the interaction effects.

1 , Time of maceration; 2 , type of yeast; 3 : Concentration of sulphur dioxide.

a Significant $(p<0.05)$. 
red Tempranillo wines, while non-anthocyanins such as hydroxybenzoic acid and flavanols were less affected (Monagas, GomézCordovés, \& Bartolomé, 2007). During the first week of vinification few monomeric polyphenols were adsorbed on the yeast walls. The low and high polymeric tannins were not adsorbed and remained into the wine. Only polar condensed tannins have higher affinities of adsorption on yeast walls (Mazauric \& Salmon, 2005).

It can be assumed that Macedonian and French yeast strains may exhibit different affinities to anthocyanins, resulting in lower adsorption of these classes of phenolics on the walls of Macedonian yeast "Vinalco". This may delay the polymerisation process in comparison with French yeast "Levuline CHP" (Caridi et al., 2004). The other reason for higher antioxidant activity of wines produced with "Vinalco" may be due to different kinetics of ethanol formation by the two applied yeasts strains. The possibility of faster fermentation leads to a higher percentage of alcohol and better extraction of polyphenols from skin and seeds of the grapes. The effect of yeast was proven by statistical analysis in Tables 4 and 5 (factor $x_{2}$ for Vranec wines 0.015 and for Merlot wines 0.000).

\subsection{Effect of $\mathrm{SO}_{2}$}

$\mathrm{SO}_{2}$ plays an important role as an antioxidant and antimicrobial agent during the winemaking process. Thus, it inactivates grape enzymes, such as polyphenoloxidases, thus protecting the polyphenols from oxidation and precipitation during the fermentation process (Castellari et al., 1998).

The expectation that higher concentrations of $\mathrm{SO}_{2}$ will increase the concentration of trans-piceid and its aglycone form in wines is not common for all wines. This effect was only observed for transpiceid in Merlot wines with 3 and 6 days of maceration time, but the difference is not statistically significant. As far as trans-resveratrol is concerned, higher concentrations of trans-resveratrol were observed in wines produced with $30 \mathrm{ppm} \mathrm{SO}_{2}$ in comparison with those produced with $70 \mathrm{ppm} \mathrm{SO}_{2}$. The difference is statistically significant as the $p$-value is 0.002 (Table 3 ).

The effect of $\mathrm{SO}_{2}$ dosage is in agreement with the findings of Castellari et al. (1998) who explained that $\mathrm{SO}_{2}$ did not increase the extraction of resveratrol from grapes, but reduced its oxidation during the pre-fermentative phase when the concentrations of piceid and its aglycone are lower.

Regarding antioxidant activity, the effect of $\mathrm{SO}_{2}$ was statistically significant only for Vranec wines because those wines were richer in polyphenols than Merlot wines (factor $x_{3}$ is 0.000). Vranec wines produced with the same vinification procedure showed higher antioxidant capacity with application of $70 \mathrm{mg} / \mathrm{L} \mathrm{SO} \mathrm{S}_{2}$. Comparing the difference between values of antioxidant activity, it can be concluded that a higher dosage of sulphur dioxide improves the extraction of polyphenols in Vranec wines for both 3 and 10 days of maceration. Even the antioxidant activity of Merlot wines following 3 and 6 days of maceration produced with $70 \mathrm{ppm} \mathrm{SO}_{2}$ is slightly higher, but the difference is not statistical significant. Higher levels of $\mathrm{SO}_{2}$ did not have a significant effect on Merlot wines probably due to their lower level of polyphenols. $\mathrm{SO}_{2}$ as an antioxidant obviously did not contribute significantly to the total antioxidant activity of red wines because of the high concentrations of polyphenolic compounds (Mareschi, François-Collange, \& Suschetet, 1992).

\section{Conclusion}

In general, variety and maceration time had the highest effect on the concentration of stilbenes and resulting antioxidant activity in both types of red wines. Merlot wines contained significantly higher concentrations of trans-piceid in comparison with Vranec wines. On the other hand, the antioxidant activity was higher in Vranec wines due to the level of other polyphenols other than stilbenes. The results from our analyses suggest highest concentrations of both stilbenes after 10 days of maceration. The tendency was the same for antioxidant activity of wines from both varieties. Concentrations of both stilbenes were higher by application of French yeast rather than Macedonian yeast. In contrast, higher antioxidant activity was measured in wines produced by application of Macedonian yeast "Vinalco". From this relationship we can conclude that anthocyanins and other polyphenols make a higher contribution to the overall antioxidant activity than do stilbenes. The amount of $\mathrm{SO}_{2}$ did not significantly influence the concentration of stilbenes and antioxidant capacity in the wines analysed.

\section{Acknowledgement}

Financial support from Deutscher Akademischer Austausch Dienst (DAAD) for Sanja Kostadinović is gratefully acknowledged.

\section{References}

Abril, M., Negueruela, A. I., Pérez, C., Juan, T., \& Estopañán, G. (2005). Preliminary study of resveratrol content in Aragon red and rose wines. Food Chemistry, 92 729-736.

Atanacković, M., Petrović, A., Jović, S., Gojković-Bukarica, L., Bursać, M., \& Cvejić, J (2012). Influence of wine making techniques on the resveratrol content, total phenolic content and antioxidant potential of red wines. Food Chemistry, 131, 513-518.

Barnard, M. J., \& Linter, S. P. (1992). Wine and coronary heart disease. The Lancet $340,313-314$

Budić-Leto, I., Gracin, L., Lovrić, T., \& Vrhovsek, U. (2008). Effects of maceration conditions on the polyphenolic composition of red wine 'Plavac mali'. Vitis, 47 , 245-250.

Caridi, A., Cufari, A., Lovino, R., Palumbo, R., \& Tedesco, I. (2004). Influence of yeast on polyphenol composition of wine. Food Technology and Biotechnology, 42 37-40.

Castellari, M., Spinabelli, U., Riponi, C., \& Amati, A. (1998). Influence of some technological practices on the quantity of resveratrol in wine. Zeitschrift für Lebensmittel-Untersuchung und -Forschung A, 206, 151-155.

Feijóo, O., Moreno, A., \& Falqué, E. (2008). Content of trans- and cis-resveratrol in Galician white and red wines. Journal of Food Composition and Analysis, 21 608-613.

Gerogiannaki-Christopoulou, M., Athanasopoulous, P., Kyriakidis, N., Gerogiannaki, I. A., \& Spanos, M. (2006). Trans-resveratrol in wines from the major Greek white and red varieties. Food Control, 17, 700-706.

Gil-Muñoz, R., Gómez-Plaza, E., Martínez, A., \& López-Roca, J. M. (1999). Evolution of phenolic compounds during wine fermentation and post-fermentation: Influence of grape temperature. Journal of Food Composition and Analysis, 12, 259-272.

Gil-Muñoz, R., Gómez-Plaza, E., Martínez, A., \& López-Roca, J. M. (1997). Evolution of the CIELAB and other spectrophotometric parameters during wine fermentation. Influence of some pre and postfermentative factors. Food Research International, 30, 699-705.

Kallithraka, S., Arvanitoyannis, I., El-Zajouli, A., \& Kefalas, P. (2001). The application of an improved method for trans-resveratrol to determine the origin of Greek red wines. Food Chemistry, 75, 355-363.

Kovac, V., Alonso, E., Bourzeix, M., \& Revilla, E. (1992). Effect of several enological practices on the content of catechins and proanthocyanidins of red wines. Journal of Agricultural and Food Chemistry, 40, 1953-1957.

La Torre, G. L., Laganà, G., Bellocco, E., Vilasi, F., Salvo, F., \& Dugo, G. (2004) Improvement on enzymatic hydrolysis of resveratrol glucosides in wine. Food Chemistry, 85, 259-266.

Lee, J., \& Rennaker, C. (2007). Antioxidant capacity and stilbene contents of wines produced in the Snake River Valley of Idaho. Food Chemistry, 105, 195-203.

Lucena, A. P. S., Nascimento, R. J. B., Maciel, J. A. C., Tavares, J. X., Barbosa-Filho, J. M. \& Oliveira, E. J. (2010). Antioxidant activity and phenolics content of selected Brazilian wines. Journal of Food Composition and Analysis, 23, 30-36.

Mareschi, J. P., François-Collange, M., \& Suschetet, M. (1992). Estimation of sulphite in food in France. Food Additives and Contaminants, 9, 541-549.

Mazauric, J. P., \& Salmon, J. M. (2005). Interaction between yeast lees and wine polyphenols during simulation of wine aging. I. Analysis of remnant polyphenolic compounds in the resulting wines. Journal of Agricultural and Food Chemistry, 53, 5647-5653.

Mazza, G., Fukumoto, L., Delaquis, P., Girard, B., \& Ewert, B. (1999). Anthocyanins phenolics, and color of Cabernet Franc, Merlot, and Pinot Noir wines from British Columbia. Journal of Agricultural and Food Chemistry, 47, 4009-4017.

Monagas, M., Goméz-Cordovés, C., \& Bartolomé, B. (2007). Evaluation of different Saccharomyces cerevisiae strains for red winemaking. Influence of the 
anthocyanin, pyranoanthocyanin and non-anthocyanin phenolic content and colour characteristics of wines. Food Chemistry, 104, 814-823.

Morata, A., Gómez-Cordovés, M. C., Suberviola, J., Bartolomé, B., Colomo, B., \& Suárez, J. A. (2003). Adsorption of anthocyanins by yeast cell walls during the fermentation of red wines. Journal of Agricultural and Food Chemistry, 51 4084-4088.

Pezet, R., \& Cuenat, Ph. (1996). Resveratrol in wine: extraction from skin during fermentation and post-fermentation standing of must from Gamay grapes. American Journal of Enology and Viticulture, 47, 287-290.

Pour Nikfardjam, M. S., Márk, L., Avar, P., Figler, M., \& Ohmacht, R. (2006). Polyphenols, anthocyanins, and trans-resveratrol in red wines from the Hungarian Villány region. Food Chemistry, 98, 453-462.

Poussier, M., Guilloux-Benatier, M., Torres, M., Heras, E., \& Adrian, M. (2003) Influence of different maceration techniques and microbial enzymatic activities on wine stilbene content. American Journal of Enology and Viticulture, 54 261-266.

Re, R., Pellegrini, N., Proteggente, A., Pannala, A., Yang, M., \& Rice-Evans, C. (1999) Antioxidant activity applying an improved ABTS radical cation decolorization assay. Free Radical Biology and Medicine, 26, 1231-1237.
Rodríguez-Delgado, M. A., González, G., Pérez-Trujillo, J. P., \& García-Montelongo, F. J. (2002). trans-Resveratrol in wines from the Canary Islands (Spain). Analysis by high performance liquid chromatography. Food Chemistry, 76, 371-375.

Spranger, M. I., Clímaco, M. C., Sun, B., Eiriz, N., Fortunato, C., Nunes, A., et al. (2004). Differentiation of red winemaking technologies by phenolic and volatile composition. Analytica Chimica Acta, 513, 151-161.

Stervbo, U., Vang, O., \& Bonnesen, C. (2007). A review of the content of the putative chemopreventive phytoalexin resveratrol in red wine. Food Chemistry, 101, 449-457.

Vacca, V., Leccis, L., Fenu, P., Pretti, L., \& Farris, G. A. (1997). Wine yeasts and resveratrol content. Biotechnology Letters, 19, 497-498.

Vrhovsek, U. Wendelin, S. \& Eder, R (1997). Effects of various vinification techniques on the concentration of cis- and trans-resveratrol and resveratrol glucoside isomers in wine. American Journal of Enology and Viticulture, 48, 214-219.

Wilkens, A., Rentzsch, M., \& Winterhalter, P. (2008). Non-flavonoid phenolic compounds. In C. Polo \& M. V. Moreno-Arribas (Eds.), Wine chemistry and biochemistry (pp. p. 4.3). New York: Springer. 